\title{
Análise ergonômica dos postos de trabalho da linha de produção de placas de borracha sintética em uma fábrica de calçados
}

Diante de uma economia globalizada, as empresas têm procurado acirradamente aumentar a produção e a qualidade de seus produtos, com custos cada vez menores, o que tem resultado na intensificação do trabalho e gerado condições laborais inadequadas. Nessa perspectiva, a presente pesquisa tem por objetivo analisar ergonomicamente os postos de trabalho que integra a linha de produção de placas de borracha sintética em uma fábrica de calçados, localizada na cidade de Juazeiro do Norte (CE). Metodologicamente, essa pesquisa possui abordagem descritiva-exploratória, qualitativa e quantitativa, no qual contemplou revisão bibliográfica e pesquisa de campo. $O$ estudo estendeu-se aos seis postos de trabalho ao longo da linha de produção das placas de borrachas: pesagem; mistura; calandragem; resfriamento; vulcanização; e divisão. As visitas à fábrica se procederam por um minucioso acompanhamento do processo produtivo, onde foi realizado entrevistas com os trabalhadores e gestores. Após a avaliação dos postos de trabalho, ficou evidente que esses funcionários estão expostos a ambientes laborais ruidosos, quentes e com iluminação ineficiente, aliada a atividade repetitiva e intensa. Assim, algumas recomendações evidenciam os pontos a serem corrigidos pela empresa na célula de produção, com a finalidade de adequar o trabalho real às aptidões e limitações físicas do seu corpo de operários.

Palavras-chave: Borracha sintética; Calçados; Ergonomia; Segurança do trabalho.

\section{Ergonomic analysis of synthetic rubber slab production line jobs in a shoe factory}

\begin{abstract}
Faced with a globalized economy, companies have been trying hard to increase the production and quality of their products, with ever lower costs, which has resulted in labor intensification and inadequate working conditions. From this perspective, the present research aims to ergonomically analyze the jobs that integrate the synthetic rubber slab production line in a shoe factory, located in the city of Juazeiro do Norte (CE). Methodologically, this research has a descriptiveexploratory, qualitative and quantitative approach, which included literature review and field research. The study extended to six jobs along the rubber slab production line: weighing; mixture; calendering; cooling; vulcanization; and division. The visits to the factory were carried out by a thorough monitoring of the production process, where interviews were conducted with workers and managers. After the job evaluation, it became evident that these employees are exposed to noisy, hot and inefficiently lit working environments, combined with repetitive and intense activity. Thus, some recommendations highlight the points to be corrected by the company in the production cell, in order to adapt the actual work to the skills and physical limitations of its workforce.
\end{abstract}

Keywords: Synthetic rubber; Footwear; Ergonomics; Workplace safety.

Topic: Engenharia do Trabalho

Reviewed anonymously in the process of blind peer
Received: $14 / 04 / 2019$

Approved: 16/06/2019
Ivone Martins da Silva

Universidade Regional do Cariri, Brasil

http://lattes.cnpq.br/8333224842639223

ivone-16martins@hotmail.com

Esdras Alex Freire de Oliveira

Universidade Regional do Cariri, Brasil

http://lattes.cnpq.br/4693470747465264

esdras-alex@hotmail.com

José Gonçalves de Araújo Filho

Universidade Regional do Cariri, Brasil

http://lattes.cnpq.br/4909589002760742

araujo.filho@urca.br
Referencing this:

SILVA, I. M.; OLIVEIRA, E. A. F.; ARAÚJO FILHO, J. G.. Análise ergonômica dos postos de trabalho da linha de produção de placas de borracha sintética em uma fábrica de calçados. Revista Brasileira de Administração Científica, v.10, n.2, p.137-153, 2019. DOI: http://doi.org/10.6008/CBPC2179-684X.2019.002.0010 


\section{INTRODUÇÃO}

As intensas mudanças econômicas e tecnológicas que vêm ocorrendo mundialmente têm exigido cada vez das empresas eficiência e flexibilidade nos processos de trabalho. Segundo Pinto et al. (2018), frente aos diversos desafios impostos pela mundialização da economia, os processos produtivos empresariais necessariamente precisam ser mais eficientes em termos de qualidade, produtividade e prazos de entrega dos produtos, o que tem resultado na intensificação do trabalho e gerado condições laborais inadequadas.

Conforme Ribeiro et al. (2015), apesar de as organizações empresariais brasileiras estarem de uma certa forma focadas em promover um ambiente de trabalho adequado e benéfico para os seus colaboradores, as mesmas ainda se deparam com inúmeros problemas que pode comprometer a saúde física e psicológica de seus funcionários, como: ritmo acelerado de trabalho; atividades monótonas e repetitivas; e ambiente físico mal ventilados, quentes, ruidosos e com mobiliário inapropriado. Esses problemas estão presentes em quase todos os processos produtivos industriais, sendo responsáveis por ocasionar diversas doenças e acidentes nos locais de trabalho.

Dentre as doenças mais prevalentes nos locais laborais, estão as Lesões por Esforços Repetitivos/Distúrbios Osteomusculares Relacionados ao Trabalho (LER/DORT), no qual está diretamente relacionado à organização do trabalho e pode ocasionar sérios danos à saúde do trabalhador, por acometer lesões em várias articulações do corpo. Estas doenças são decorrentes da utilização excessiva imposta ao sistema musculoesquelético por determinados esforços no trabalho, e da falta de tempo para recuperação destas estruturas (TORRES, 2016).

É nessa perspectiva que surge a necessidade de estudos que abordem aspectos do cotidiano no ambiente laboral, em especial, a precarização das condições de trabalho, a introdução de novas tecnologias e os modos de organização e gestão dos processos produtivos. Para Oliveira (2018), a análise dos fatores de riscos que possivelmente venha a existir em um estabelecimento industrial, deve ser realizada em todos os recintos do empreendimento, e a partir desta análise, efetuar o levantamento das circunstâncias que possa comprometer a saúde e a integridade física do trabalhador, mantendo atenção nas características de trabalho de cada indivíduo.

A premissa aqui levantada é que as condições de trabalho nesse ramo de atividade industrial forneçam e condicionem um ambiente de trabalho capaz de promover ou não a produtividade, a saúde e a segurança do operador. Desse modo, é importante identificar os riscos ocupacionais que eventualmente decorre dos procedimentos operacionais das máquinas, do ambiente e das relações de trabalho, que pode comprometer a segurança e a saúde dos trabalhadores. Mas, como aumentar a produtividade industrial sem acarretar danos psicofisiológicos ao trabalhador?

O crescimento do setor calçadista na região do Cariri tem possibilitado a introdução de novas tecnologias aplicadas à automação dos processos de mistura na produção de componentes plásticos. A indústria calçadista em questão produz predominantemente calçados sintéticos a partir de elastômeros com o emprego de diversos maquinário de média e grande complexidade, tais como injetoras de plástico, 
extrusoras, prensas hidráulicas, misturadores, dentre outros. Segundo a Associação Brasileira das Indústrias de Calçados - ABICALÇADOS, no ano de 2017, cerca de $28 \%$ da produção nacional de calçados está concentrada no estado do Ceará, sendo que o polo de Juazeiro do Norte detém quase $9 \%$ da produção estadual.

Sendo assim, essa pesquisa tem como objetivo analisar ergonomicamente os postos de trabalho que integram a linha de produção de placas de borracha sintética em uma fábrica de calçados, localizada na cidade de Juazeiro do Norte/Ceará. A Análise Ergonômica do Trabalho (AET) visa aplicar os conhecimentos da ergonomia para analisar, diagnosticar e corrigir uma situação real de trabalho (IIDA, 2005).

Em relação aos resultados almejados, esse estudo tem como finalidade conscientizar os gestores da referida fábrica de calçados sobre a importância da adequação as exigências estabelecidas na NR-17 (Ergonomia), bem como oferecer subsídios para que seu corpo de operários desfrute de um ambiente com condições de trabalho mais adequado e em conformidade com a legislação de SST (Saúde e Segurança do Trabalho) vigente.

\section{REVISÃO TEÓRICA}

Sabemos que os referentes problemas, em relação à saúde do trabalhador, não são baseados em acontecimentos recentes; de fato, é algo que há muito tempo já vem trazendo as devidas preocupações, o que precisa ser debatido, e com a ergonomia, procurar a melhor adequação para solucionar tais problemas. Segundo Antunes et al. (2015), desde o século XX, com a grande produção em massa imposta pela expansão do capitalismo ocorrido durante o período taylorista-fordista, surgiram novas formas de acidentes e moléstias relacionada ao trabalho, que passaram a fazer parte do ambiente laboral. Ao longo do tempo, disfunções ocorrem no processo produtivo de trabalho, gerando aumento da carga física e mental dos trabalhadores (RIBEIRO et al., 2015).

Em meio a uma economia extremamente capitalista, o amparo da legislação referente ao trabalho é fator necessário para que os profissionais da área de SST (Saúde e Segurança do Trabalho) possam alcançar resultados eficientes, que diminua ou mesmo elimine as ameaças impostas a saúde humana no ambiente de trabalho. Porém, "fornecer ao trabalhador condições de trabalho ergonomicamente adequadas, antes de ser uma imposição legal, revela-se um importante diferencial para as modernas organizações" (SILVA, 2009).

A norma regulamentadora NR-17 (BRASIL, 1978), que trata especificamente da ergonomia, tem por objetivo estabelecer os parâmetros mínimos que permite a adaptação das condições de trabalho às características psicofisiológicas dos trabalhadores, de modo a proporcionar um máximo de conforto, segurança e um bom andamento do processo laboral. Essa norma aponta a responsabilidade de o empregador realizar a análise ergonômica do trabalho, ressalta que acidentes e doenças relacionados ao trabalho são agravos previsíveis e, portanto, evitáveis (PINTO et al., 2018).

Estabelecer melhorias para as condições organizacionais e ambientais em que estão submetidos os trabalhadores, tendo por referência as recomendações expressas na NR-17, requer uma análise das práticas em campo, que inclui: as atividades relacionadas ao levantamento, transporte e descarga de materiais; ao 
mobiliário; as condições do arranjo físico; os equipamentos em geral de trabalho e em relação a própria organização do trabalho (FERREIRA, 2015).

Para garantir a efetividade de tais recomendações, que inclui o cumprimento das exigências legais atuais, é necessário haver responsabilidade e comprometimento de todas as partes envolvidas da organização desde a administração superior até a parte operacional composta pelos funcionários.

A maior importância do projeto e organização do trabalho, porém, diz respeito à sua atuação como elemento que fornece aos funcionários condições de trabalho que maximizam a produtividade e, ao mesmo tempo, protegem sua integridade física e psicológica (SILVA, 2009). A Análise Ergonômica do Trabalho - AET é uma abordagem da ergonomia centrada na atividade, que confronta o trabalho projetado pela engenharia de métodos e as condições de sua execução com o trabalho realmente desenvolvido pelos trabalhadores. É um meio de revelar novas questões sobre o desempenho do homem no trabalho, mas também uma abordagem original para a transformação e a concepção dos meios técnicos e organizacionais de trabalho (GUÉRIN, 2001).

Segundo lida (2005) o enfoque ergonômico tende a desenvolver postos de trabalho que reduzem as exigências biomecânicas e cognitivas, procurando colocar o colaborador em uma boa postura de trabalho, no qual, o mesmo é comparado a uma "vestimenta" bem adaptada, posicionada em um ambiente onde possa realizar o trabalho com conforto, eficiência e segurança. Nessa pesquisa será adotada a definição do conceito sobre ergonomia da International Ergonomics Association - EIA:

A Ergonomia (ou Fatores Humanos) é uma disciplina científica relacionada ao entendimento das interações entre os seres humanos e outros elementos ou sistemas, e à aplicação de teorias, princípios, dados e métodos a projetos a fim de otimizar o bem-estar humano e o desempenho global do sistema.

Na visão de lida (2005), a ergonomia é o estudo da adaptação do homem ao trabalho, levando em conta, primeiramente, as características do trabalhador, para que, posteriormente, seja projetado o trabalho a ser executado, considerando as limitações e capacidades físicas dos funcionários. O objetivo prático da ergonomia é a adaptação do posto de trabalho, dos instrumentos, das máquinas, dos horários e do meio ambiente às exigências do homem (RIBEIRO et al., 2015).

A ergonomia apresenta situações reais de trabalho, analisando a maneira que possa ser confortável e bem-sucedida as realizações das atividades, tendo em vista a finalidade de humanização e avanço do sistema de trabalho (ORMELEZ et al., 2010). Dessa forma, a ergonomia se caracteriza como uma intervenção técnica aplicada no ambiente laboral capaz de reestruturar a atual organização do trabalho de uma empresa e, assim, possibilitar a neutralização ou a minimização dos fatores que acarretam a intensificação do trabalho e o surgimento de patologias ocupacionais.

Em ergonomia, a postura e o movimento corporal possuem uma considerável relevância, pois, no ambiente de trabalho, o colaborador se depara com inúmeras atividades que exige movimentos do corpo, como levantamento e transporte de cargas, digitação, dentre outros. Posturas, movimentos e postos de trabalho inadequados podem provocar: estresse; fadiga muscular e dores em várias regiões do corpo como pescoço, costas, ombros, punhos (KROEMER et al., 2005). 
A análise ergonômica do trabalho é um processo construtivo e participativo para a resolução de um problema complexo que exige o conhecimento das tarefas, da atividade desenvolvida para realizá-las e das dificuldades enfrentadas para se atingirem o desempenho e a produtividade exigidos.

Em atividades que exigem a elevação por bastante tempo dos membros superiores, há possíveis incidência de dores no pescoço e na região dos ombros. Geralmente, essas dores podem se agravar quando existe movimentos repetitivos intensos desses membros juntamente com a aplicação de forças. Outro ponto a ser ressaltado, é em relação a posição do punho (região do membro superior correspondente à articulação do antebraço com a mão) durante a jornada de trabalho, pois nessa região pode ocorrer inflamações quando submetido por longo período em uma única posição inclinada, o que pode resultar posteriormente em dores e formigamentos (DUL et al., 2012).

As sobrecargas recebidas, devido à realização das atividades, podem ser divididas em problemas reversíveis, que são aqueles que apresentam curta duração, como as dores ocasionada pela fadiga muscular e em problemas persistentes, onde as dores não desaparecem após a atividade ser interrompida e, em muitos casos, é mais comum ocorrer em trabalhadores mais velhos. Outra observação importante é a ocorrência das lesões musculoesqueléticos ou osteomuscular, que caso se prologuem por muitos anos, podem se transformar em um problema crônico (KROEMER et al., 2005). As LER/DORT, especialmente as que atingem os membros superiores, vêm apresentando prevalência crescente nas sociedades ocidentais e sua ocorrência alcança 50 a 80\% da população economicamente ativa (JANUÁRIO et al., 2019). Lourinho (2011) afirma que

O distúrbio osteomuscular relacionado ao trabalho (DORT) é usado para determinar afecções que podem lesar tendões, sinóvias, músculos, nervos, fáscias e ligamentos, de forma isolada ou associada, com ou sem degeneração dos tecidos, atingindo, principalmente os membros superiores, região escapular, pescoço e coluna lombar.

Deste modo, a elaboração desta AET permite definir alguns conceitos para o projeto das estações de trabalho, capaz de proporcionar o exercício da força muscular no ambiente laboral com o máximo de eficiência e o mínimo de esforço físico. Logo, o estudo aplicado neste ramo de atividade industrial deve ser bem detalhado levando em consideração todas as características dos trabalhadores.

\section{METODOLOGIA}

\section{Objeto de Estudo}

O estudo estendeu-se aos seis postos de trabalho ao longo da linha de produção das placas de borracha sintéticas em uma indústria do ramo calçadista. Os postos de trabalho avaliados são: formulação (pesagem); mistura (banbury); calandragem (homogeneização); resfriamento (laminação); vulcanização (prensagem) e divisão (rachadeiras). Adotou-se de acordo com lida (2005), o conceito de posto de trabalho como sendo a menor unidade produtiva, que geralmente envolve um homem e seu ambiente laboral.

Para atingir os objetivos propostos, este estudo foi embasado por uma pesquisa exploratóriadescritiva de caráter qualitativo e quantitativo. As pesquisas exploratórias têm como propósito proporcionar maior familiaridade com o problema, com vistas a torná-lo mais explícito ou a construir hipóteses (GIL, 2017). 
Andrade (2010) ressalta que na pesquisa descritiva, "os fatos são observados, registrados, analisados, classificados e interpretados, sem que o pesquisador interfira neles".

Na pesquisa bibliográfica foram utilizadas fontes como artigos científicos publicados em periódicos, livros especializados e em sítios na internet, abordando principalmente as questões relacionadas a indústria calçadista, a produção de elastômeros e sobre a ergonomia. Junto a empresa, foram entrevistados vários trabalhadores envolvidos diretamente com a linha de produção.

\section{Procedimentos de Coleta de Dados}

A coleta de dados procedeu-se através de observação direta, entrevistas semiestruturadas com os trabalhadores, registro fotográfico e a utilização de equipamento digital para aferição dos níveis de ruído e iluminância, no qual, foram verificados o processo produtivo e o método de trabalho adotado em cada posto, levando-se em conta os aspectos gerais da edificação e a percepção dos trabalhadores quanto às condições do seus ambientes laborais, ritmo de trabalho, repetitividade, fadiga ou desconforto em regiões do corpo. A participação dos gestores e dos trabalhadores ocorreu por adesão após a uma explanação referente a pesquisa a ser realizada e assumir compromisso de não identificar qualquer um que foi entrevistado durante a elaboração desse estudo.

\section{Procedimentos de Análise de Dados}

Os dados que subsidiaram a pesquisa foram avaliados de forma qualitativa e quantitativa. Pelo aspecto qualitativo, foram consideradas as entrevistas realizadas com os trabalhadores, onde foram apreciadas as opiniões deles em relação as condições do seu ambiente laboral. Também foram levadas em consideração as observações realizadas nos postos de trabalho durante as visitas ao local fabril, tendo em vista as recomendações expressas nas Normas Regulamentadoras (NRs) do Ministério do Trabalho e Emprego (MTE).

Sob o aspecto quantitativo, foram avaliados, por meio de instrumento digital (equipamento com multifunções da marca MASTECH e modelo MS8229), os níveis de ruído e iluminância, os quais, foram comparados aos parâmetros estabelecidos nas normas NR-17 referente a ergonomia, NR-15 (atividades e operações insalubres) e na norma técnica NBR 5413 (Iluminância de interiores) da Associação Brasileira de Normas Técnicas (ABNT).

\section{RESULTADOS E DISCUSSÃO}

A referida fábrica é uma empresa do ramo calçadista fundada em 1963, que além de atuar no mercado nacional, exporta hoje para mais de 20 países, com cerca de $35 \%$ da produção anual destinada ao mercado internacional. O prédio fabril fica localizado na cidade de Juazeiro do Norte (CE). A pesquisa foi realizada na linha de produção de placas de borracha sintéticas manufaturadas a base de polímeros (EVA, SBR e blendas). As principais etapas de produção de solados para calçados são divididas basicamente em: pesagem (formulação), mistura (banbury), calandragem (homogeneização), resfriamento (laminação), 
vulcanização (prensagem) e divisão (rachadeiras). A empresa produz alças, sandálias e placas de vários modelos em diversas cores e estampas.

O processo de produção de tais placas requer bastante conhecimento das fórmulas, das características da matéria-prima e do manuseio dos equipamentos, o que necessita de uma mão de obra experiente. Uma das principais características do processo produtivo é a expansão do material, que proporciona o aumento do volume por meio de reações químicas a determinadas temperaturas. Cada etapa do processo é inteiramente importante para que o produto saia com a qualidade desejada.

Além dos polímeros SBR e EVA, devemos considerar as misturas poliméricas, ou blendas, onde dois ou mais polímeros são combinados para obtenção de um novo material com propriedades diversas. A produção de blendas é uma forma de obter novos materiais poliméricos sem haver a necessidade de investir no desenvolvimento de novos monômeros ou de novos processos de polimerização.

Em praticamente todos os tipos de materiais poliméricos, empregam-se aditivos para melhorar ou para aprimorar as propriedades finais do produto. São adicionados estabilizantes, antioxidantes, fotoestabilizantes, estabilizantes de processo, lubrificantes, cargas minerais, corantes etc. Com o aumento e a diversificação das aplicações de materiais poliméricos, a aditivação ou formulação, também tem se tornado cada vez mais específica para cada tipo de aplicação. Na figura 1, podem ser verificadas as etapas do processo de produção das placas de borracha sintética na indústria de calçados.

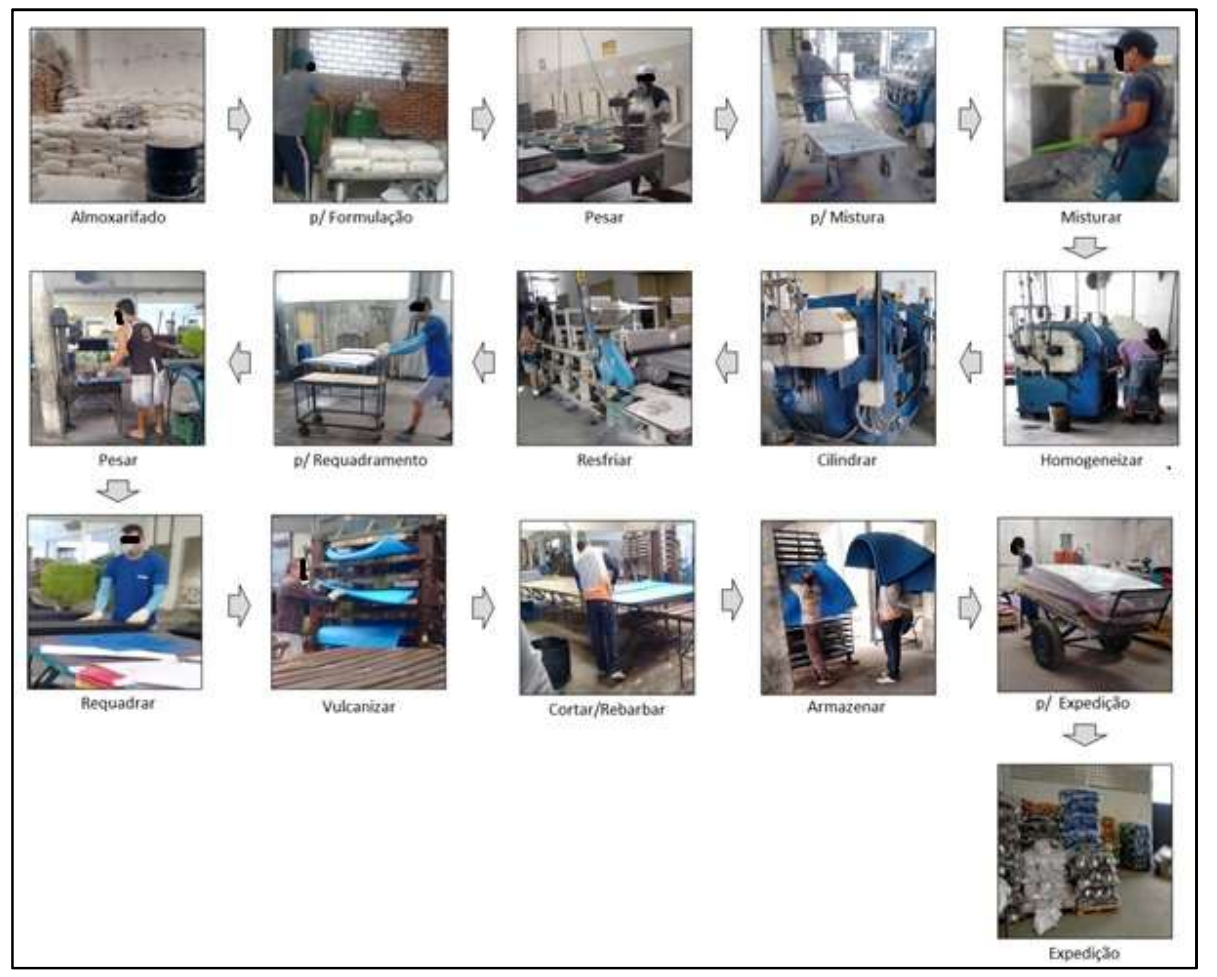

Figura 1: Etapas da fabricação das placas de borrachas

Muitas vezes, a aditivação do composto polimérico é realizada usando uma mistura concentrada de aditivos chamada de masterbatch, sendo que tal mistura é adicionada posteriormente ao polímero durante o processamento. Os masterbatch são preparados por empresas especializadas na produção de formulações. Nesta etapa de aditivação, o colaborador deve tomar bastante cuidado durante a preparação da composição, 
pois na formulação da mistura deve verificar se o polímero base é o mesmo com o qual ele vai ser adicionado durante o processamento.

É importante ressaltar que alguns polímeros que têm propriedades de processamento muito semelhantes como o polietileno e o polipropileno, por exemplo, podem ter mecanismos de reações de degradação muito diferentes, o que pode resultar no decorrer do processo em um composto com propriedades físico-química de baixa qualidade. A análise ergonômica desenvolvida nessa pesquisa vai se ater aos postos de trabalho ao longo das etapas do processo de fabricação das placas de borrachas.

\section{Formulação/Pesagem}

Nesta etapa do processo produtivo, é realizada a pesagem das matérias-primas necessárias para as várias formulações de borrachas, como: pigmentos, negro de fumo, aceleradores, retardadores, ativadores de vulcanização, etc.. A pesagem é uma etapa de suma importância para o processo produtivo, e deve ser realizada de forma rigorosa para que toda a produção ocorra corretamente e com a mesma composição em cada item, sendo que a precisão durante esse processo é fator fundamental para garantir qualidade no produto. Essa atividade de pesagem é uma função que exige bastante atenção e prudência por parte do funcionário. Na figura 2, pode ser observado o processo de pesagem da matéria-prima.

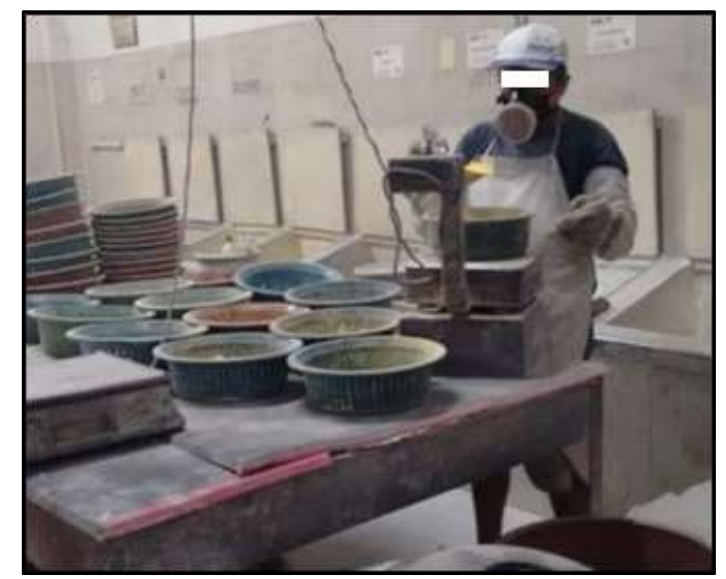

Figura 2: Posto de trabalho de pesagem.

Nesse local de trabalho existe uma bancada com $1 \mathrm{~m}$ de altura, $6 \mathrm{~m}$ de comprimento e $1 \mathrm{~m}$ de largura, sendo que essa bancada é utilizada pelo funcionário durante o desenvolvimento da tarefa. Os materiais são transportados e depositados em recipientes plásticos em cima da bancada por outro funcionário para serem posteriormente pesados. O funcionário responsável por esta atividade deve efetuá-la com bastante diligência, para que no momento da operação, não ocorra atrasos na produção por eventuais erros durante a pesagem. Além disso, essa atividade é considerada uma tarefa extremamente repetitiva, onde o funcionário realiza uma série de movimentos similares utilizando as mãos, porém, ela não exige esforço físico intenso.

O ideal para esse ambiente de trabalho é que ele esteja sempre limpo, pois no local existem muitas substâncias químicas dispersas. Em média a produção é de 120 cargas por dia e cada carga é feita em aproximadamente dois minutos, sendo que no final do expediente o funcionário deverá ter finalizado o 
processamento das devidas cargas. Uma carga constitui o somatório de todos os ingredientes necessário para a formulação do composto polimérico e devidamente ajustada às dimensões do misturador, sendo também chamado de peso de carga.

Fica evidente que esta atividade de pesagem se torna prejudicial à saúde do trabalhador, em razão de a mesma ser realizada na posição em pé e com pouco tempo para descanso. Além disso, essa tarefa é realizada por apenas um funcionário, o que acaba exigindo sua máxima permanência durante o processo de trabalho para garantir a produtividade diária. Por ser uma atividade considerada leve, realizada em uma bancada, na posição em pé e com poucos movimentos do corpo, é essencialmente recomendado para esse posto de trabalho, conforme a NR-15 (BRASIL, 1978b), que a cada 45 minutos de trabalho realizado pelo operador, o mesmo tenha pelo menos 15 minutos de descanso. Seria ideal também, que a empresa disponibilizasse acentos para descanso nesse local de trabalho.

Durante as visitas realizada a fábrica, foi verificado que o acesso a esse ambiente de trabalho é efetuado através de uma única porta tanto para entrar como para sair do recinto. No local havia placas informando a existência de produtos tóxicos, o piso não possuía marcação de segurança e tinha um extintor de incêndio instalado a base de gás carbônico $\left(\mathrm{CO}_{2}\right)$. O funcionário utilizava para realizar suas atividades laborais equipamentos de proteção individual como luvas e botas, porém, não usava protetores auriculares e fardamento adequado.

O ambiente apresentava carga térmica elevada e conforme as medições realizadas nesse recinto de trabalho, a intensidade sonora mensurada foi de $74,6 \mathrm{~dB}$, e o fator de iluminância de 280 lux. Segundo a NR17 (BRASIL, 1978), para atividades laborais que exigem do colaborador atenção constante, é recomendada as seguintes condições de conforto: níveis de pressão sonora de até $65 \mathrm{~dB}$; índice de temperatura efetiva entre 20 e 23 graus centígrados; velocidade do ar não superior a 0,75m/s e umidade relativa do ar não inferior a $40 \%$.

Conforme a NBR 5413 (ABNT, 1992), as tarefas com requisitos visuais normais, trabalho médio com maquinário e em escritórios, o grau de iluminância oscila de 500 a 1000 lux. Desse modo, é inteiramente recomendável que a empresa disponibilize EPIs adequados para os seus funcionários e os incentive a utilizarem durante toda jornada de trabalho. Os níveis de iluminação e a questão da cor para o ambiente de trabalho têm forte influência no desenvolvimento das atividades, e em caso de excesso de luminosidade, pode provocar graves problemas à saúde visual do homem (OLIVEIRA, 2018).

Conforme a prescrição da tarefa estabelecida pela empresa, as atividades nessa etapa do processo produtivo são iniciadas a partir das $6 \mathrm{~h}$ no período da manhã e finalizadas às $16 \mathrm{~h}$ no período da tarde, totalizando uma jornada diária de $9 \mathrm{~h}$ de trabalho. Durante essa jornada de trabalho, o colaborador tem uma hora para almoço e uma pausa de 15 minutos no decorrer do expediente destinada a lanches e eventuais necessidades de higiene pessoal. Esse funcionário também é responsável pela limpeza do seu próprio posto de trabalho, que normalmente é realizada no final do expediente. Após finalizada essa etapa, a matériaprima é transportada em sacos para a etapa de mistura. 


\section{Mistura/Banbury}

Nesse local de trabalho o funcionário utiliza para realizar suas atividades um misturador do tipo Banbury ${ }^{1}$. Na operação dessa máquina, o trabalhador deve seguir uma ordem pré-definida para colocar os componentes da mistura no equipamento, no qual deve seguir rigorosamente a ordem e a quantidade de cada ingrediente na formulação. Nesse tipo de misturador, o processamento das substâncias se faz em um compartimento fechado, onde estão posicionados dois rotores que giram com velocidades e sentidos diferentes. Durante o processamento, esse compartimento pode ser aquecido para facilitar a integração das substâncias secas à borracha, enquanto os rotores são internamente refrigerados através de uma circulação de água com o intuito de evitar a vulcanização prematura (scorching) da amostra.

O misturador Banbury permite maior asseio na operação e produz uma mistura homogênea em menos tempo do que é possível conseguir em um moinho aberto; porém, o material deve ser laminado pelos rolos do misturador comum para evitar o 'scorching' do composto de borracha, que além do mais são dificilmente armazenadas. Durantes as observações no local, percebe-se que o trabalho efetuado pelo operador dessa máquina de mistura é desenvolvido em sua maior parte do tempo em pé, sendo necessária realizar várias inclinações do corpo para alcançar os componentes necessário para a fabricação do produto, já que estes ficam no chão próximo à máquina. $\mathrm{Na}$ figura 3 , pode ser observada a operação do misturador pelo funcionário.

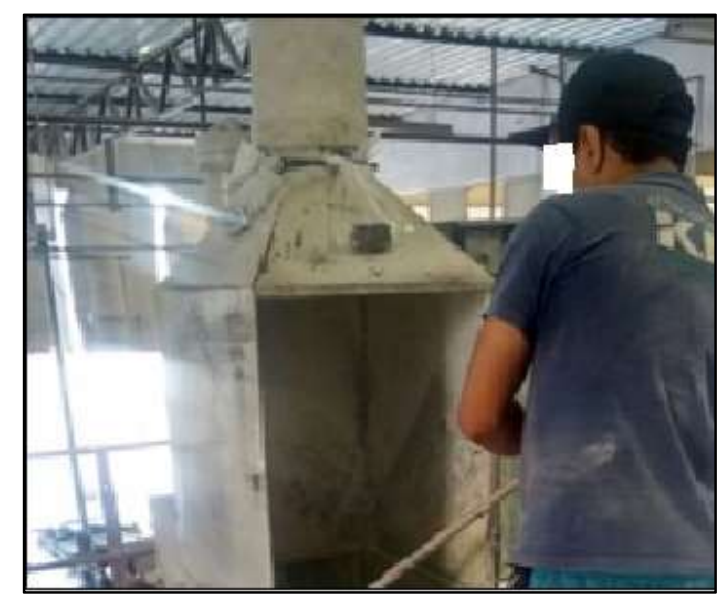

Figura 3: Posto de trabalho da mistura.

É possível perceber ainda que essa atividade é bastante repetitiva, pois os componentes da mistura devem ser colocados um por vez no misturador. Ou seja, a tarefa do operador é colocar os componentes da mistura na máquina em ordem e com bastante atenção para que a 'massa polimérica' não saia em desacordo com o esperado. Conforme entrevista realizada com o funcionário responsável pela operação desse maquinário, ele possui 29 anos de idade, $1,70 \mathrm{~m}$ de altura, trabalha a 5 anos com esse equipamento e nunca precisou se ausentar de suas atividades ocupacionais em razão de alguma enfermidade.

Segundo relato desse funcionário, ele já sofreu diversas queimaduras de grau leve durante a operação dessa máquina e quase sempre sente dores na coluna, ombros, ouvidos, porém, não sente

\footnotetext{
${ }^{1} \mathrm{O}$ inglês Fernley H. Banbury é considerado o inventor do atual misturador interno, que vulgarmente designamos por Banbury. 
problemas de visão e de insônia. Na operação dessa máquina o funcionário deve acionar o botão de liga/desliga, não exigindo, assim, esforço físico intenso para realizar essa atividade. Para manter a equipamento operando, o funcionário realiza um procedimento manual repetitivo ( 8 repetições/ciclo), que consistem em abaixar-se para pegar a matéria-prima e em sequência lançá-la dentro da máquina.

De acordo com a cronometragem realizada nessa tarefa de operação do misturador, o tempo do ciclo do processamento de uma carga foi definido em 10 minutos e 12 segundos, sendo que o funcionário consegue processar 45 cargas durante o dia. Com base no tempo de processamento de cada carga, esse funcionário passa em média 7h59min para finalizar o trabalho diário. Desse modo, o tempo de descanso desse funcionário fica restrito apenas ao período em que a matéria-prima é processada pela máquina. A limpeza desse maquinário também é realizada pelo funcionário ao final do expediente ou quando for necessário durante o processo produtivo.

A formulação das misturas é efetuada semanalmente e vistoriada pelo o dono da empresa que possui qualificação profissional em química. Esta formulação serve para encontrar o antioxidante e antiozonante adequado para evitar a degradação da borracha. As cargas são usadas para conferir algumas propriedades ao produto, como: o aumento do módulo elástico, a resistência à tração, à resistência abrasão e ao rasgamento, sendo também uma forma de baratear o artefato final. Foi constatado, durante as visitas, que no local, não existem ventiladores e nem exaustores, sendo que o funcionário estava utilizando EPIs básicos (luvas térmicas e protetores auriculares), porém, não utilizava botas e roupa apropriada para a atividade.

A limpeza do piso e da máquina de mistura é realizada com o auxílio de vassouras para que o excesso de poeira não venha a contaminar as cores do composto da mistura. Na parte superior da zona de carga, existe um sistema de exaustão que serve para captar as poeiras e os gases da câmara de processamento da máquina. Durante o intervalo de tempo em que a mistura é processada pela máquina (movimento realizado pelo pistão acoplado ao equipamento), o operador aproveita para carregar os ingredientes utilizados na composição para próximo do misturador ou mesmo para realizar as operações de limpeza, que consiste em varrer para a câmara de mistura as sobras de materiais que ficam alojados na parte superior do pistão e os agarrados às paredes do misturador na zona de carga.

A plataforma de acesso ao misturador é composta por uma estrutura de madeira elevada a aproximadamente $2 \mathrm{~m}$ de altura em relação ao piso e com duas escadas instaladas, que são utilizadas pelo colaborador para possibilitar o acesso a máquina. No local não existia marcação de segurança no piso necessário para indicar as zonas de perigo e havia somente um extintor de incêndio $\left(\mathrm{CO}_{2}\right)$ instalado no recinto. $\mathrm{O}$ ambiente do setor de mistura da empresa é amplo, porém, não contém uma boa circulação de ar. Existe no local 4 (quatro) misturadores e 4 (quatro) funcionários por horário de trabalho, sendo que essa pesquisa avaliou somente os funcionários que trabalhava durante o dia, pois a empresa também funciona no horário noturno. A jornada de trabalho desses funcionários é de 8 horas diárias, tendo apenas uma hora para almoço.

No compartimento interno do misturador a temperatura atingida é relativamente alta, o que certamente contribui para a elevação da carga térmica nesse recinto de trabalho. Foi constatado durante a 
operação desse maquinário, que o colaborador está exposto a nível de ruído em torno de 87,2dB (aferição efetuada com equipamento digital), estando dessa forma em desconformidade com NR-15 (Brasil, 1978b). Conforme essa norma o limite de ruído contínuo ou intermitente é de $85 \mathrm{~dB}$ para cada $8 \mathrm{~h}$ de exposição diária no local de trabalho sem proteção adequada.

Vale ressaltar que os funcionários realizam suas atividades diárias em local aberto, estando também submetido a ruídos advindo dos demais recintos da fábrica. A iluminação nesse local da fábrica foi mensurada em torno de 275 lux. Segundo a NBR 5413, as tarefas com requisitos visuais normais, trabalho médio de maquinário e escritório, o grau de iluminância varia de 500 a 1000 lux. Desta forma, o nível de iluminância desse recinto laboral encontra-se abaixo do recomendado.

\section{Calandragem/Homogeneização}

Durante o processo de mistura as máquinas alcançam uma temperatura de aproximadamente 170 graus centrígrados e quando passa para o processo externo na calandra (equipamento de trabalho) ocorre uma perda de temperatura em aproximadamente 90 graus. Nessa etapa do processo produtivo o material passa inicialmente por um procedimento de amaciamento antes de prosseguir com as demais etapas do processo. Na figura a abaixo pode ser verificado o processo de calandragem da matéria-prima.

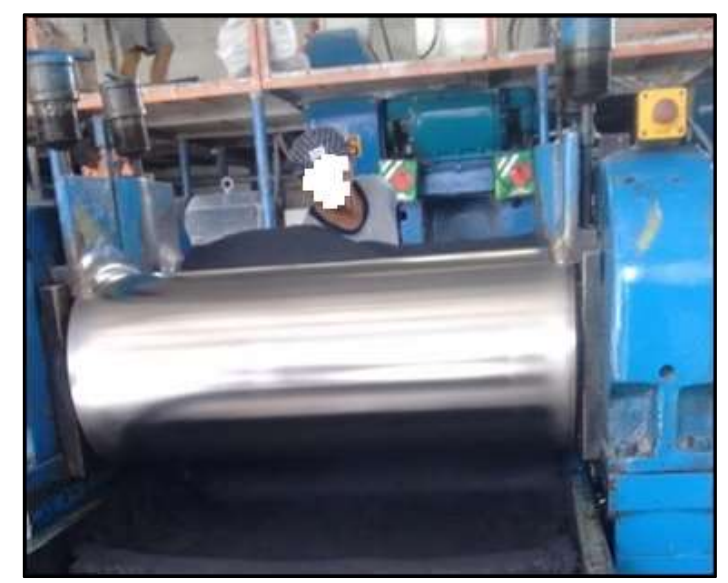

Figura 4: Posto de trabalho da calandragem.

Essa operação de calandragem exige muita atenção por parte do colaborador, sendo que ele ainda exerce bastante esforço físico e realiza vários movimentos repetitivos, o que torna sua função muito exaustiva. Segundo relato desse colaborador, ele executa essa função a 21 anos e nunca apresentou problema de saúde devido ao trabalho. Em relação ao recinto, ele considera o ambiente muito barulhento, porém, com iluminação e ventilação adequada.

Além disso, o funcionário realiza a atividade durante toda a jornada de trabalho na posição em pé. As cargas que é colocada na calandra são transportadas para esse ambiente de trabalho por outro funcionário. O funcionário responsável pelo transporte das cargas de materiais também ajuda o operador da calandra a retirar o recipiente que recebe a mistura (onde o material é depositado) e posteriormente o auxilia a colocar na máquina novamente.

Nesse posto de trabalho não foi constado as marcações de segurança no piso para delimitar a zona 
de perigo nos arredores da máquina, o local possui extintores de incêndios, os funcionários estavam utilizando alguns EPIs (luvas, botas etc.), porém, não estavam usando máscara de proteção e protetores auriculares. $\mathrm{O}$ ambiente de trabalho possui uma boa ventilação, pois era situado em um local aberto. A pressão sonora aferida pelo equipamento foi de $86,2 \mathrm{~dB}$ e a iluminância de 334 lux. Assim como os demais postos de trabalho analisados, esse local da fábrica também não está em conformidade com a legislação vigente, em relação: ao nível de ruído que deve ser de $85 \mathrm{~dB} /$ dia; aos níveis iluminância que deve estar entre o intervalo de 500 a 1000lux (conforme a NBR 5413) e em relação as delimitações de segurança que deve constar nos arredores da máquina para evitar possíveis acidentes de trabalho.

\section{Resfriamento/Laminação}

Nessa etapa do processo do produtivo o material passa por uma esteira, onde a mistura torna-se uma pequena manta e posteriormente segue adiante com a fabricação, como pode ser observado na figura 5. Essa operação de resfriamento é realizada pelo funcionário com diversos movimentos similares em curtos períodos, o que a torna extremamente repetitiva. Além disso, essa atividade é realizada na posição em pé e ainda exigi do colaborador bastante atenção. Esse funcionário considera o seu ambiente de trabalho barulhento, mas com boa ventilação.

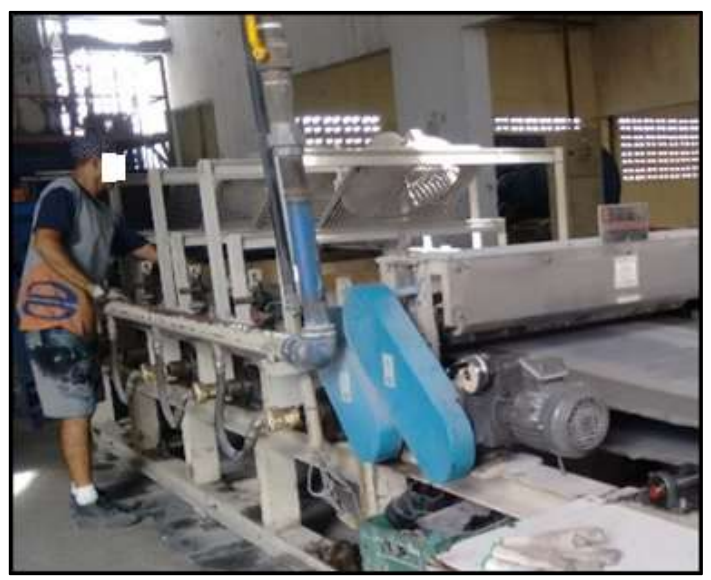

Figura 5: Posto de trabalho do resfriamento.

A mistura polimérica proveniente do processo de calandragem é transportada através de um carrinho até a etapa de resfriamento. O piso também não apresenta marcações de segurança e o local possui extintores portáteis de $\mathrm{CO}_{2}$ instalado. Foi constatado que o colaborador utiliza EPIs como luvas, bota, mas não utiliza máscara e protetores auriculares. O nível de pressão sonora mensurado foi de $89,4 \mathrm{~dB}$ e iluminância de 334lux. Nesse local da fábrica, os parâmetros avaliados não estão em conformidade com legislação vigente, sendo que a exposição aceitável de ruído é de $85 \mathrm{~dB}$ (conforme a NR-15) sem proteção e fator recomendável de iluminância de 500 a 1000lux (conforme a NBR 5413).

\section{Vulcanização/Prensagem}

Nesta etapa do processo, ocorre a reticulação e expansão do EVA, quando as placas são introduzidas nas prensas em seus platôs durante o processo de vulcanização. As principais características das placas, 
como: as dimensões e as propriedades de dureza e densidade são controladas nesta fase do processo. As placas de EVA podem ser lisas ou conter desenhos de acordo com a ferramenta utilizada, como pode verificado na figura 6 .

O funcionário realiza a aplicação de silicone na prensa para evitar a aderência do material no molde, em seguida pega o material misturado (laminado) em uma "prateleira móvel" e o insere na máquina. Logo após esse procedimento, o funcionário efetua o fechamento do molde da máquina através do acionamento de uma chave no quadro de comando, que ao ser acionada inicia o processo de vulcanização do EVA. O transporte do material é realizado por outro funcionário utilizando um carrinho até o local de pesagem. Em seguida o operador da prensa de vulcanização coloca o material na máquina e inicia o procedimento que irar definir as dimensões das placas de borrachas.

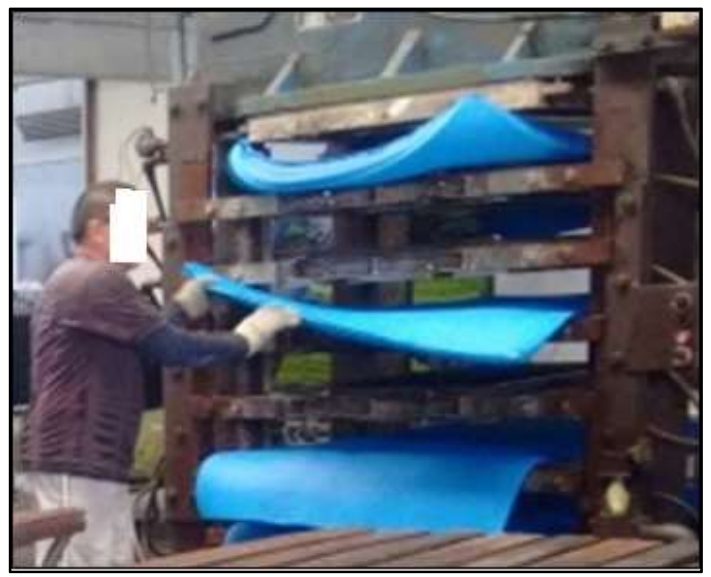

Figura 6: Posto de trabalho da vulcanização.

Assim como os demais ambiente de trabalho avaliado, o piso onde a prensa está instalada não possui as devidas marcações de segurança, sendo que no local havia uma balança para aferição do peso dos materiais e um extintor de incêndio instalado. Contatou-se também que nesse recinto ocupacional possui uma bancada elevada em $1 \mathrm{~m}$ em relação ao piso e com dimensões de $6 \mathrm{~m}$ de comprimento e $1 \mathrm{~m}$ de largura. Os funcionários utilizavam luvas, botas e máscaras, porém, nem sempre utilizavam o protetor auricular durante a realização da atividade.

Esse ambiente de trabalho apresenta temperatura elevada e conforme as medições realizadas, o nível de pressão sonora foi de $105,1 \mathrm{~dB}$ e fator de iluminância de 137 lux. O ruído apresentado nessa etapa do processo produtivo foi significativamente elevado, estando assim, acima dos limites de tolerância aceitável pela legislação ( $85 \mathrm{~dB}$ por $8 \mathrm{~h}$ /dia de exposição máxima sem proteção adequada, segundo NR-15). Em relação ao fator de iluminância o recomendável para esse recinto de trabalho é de 500 a 1000 lux, conforme NBR 5413.

Existem algumas medidas eficientes para proteção contra fontes produtoras de pressão sonora que serão descritas a seguir: pode-se optar pelo enclausuramento das máquinas que estão produzindo ruído intenso, ou optar pela substituição por outras mais silenciosas, adotar medidas de manutenções periódicas nos equipamentos, como lubrificação das partes móveis e substituição de peças desgastadas. Caso essas medidas não eliminem totalmente o ruído no ambiente, o empregador deve oferecer protetores auriculares para os indivíduos que estejam expostos ao intenso barulho. 


\section{Divisão/Rachadeiras}

Após a matéria-prima ganhar o volume e espessura desejada, as placas são encaminhadas para o acabamento. As atividades realizadas durante o processo de acabamento são: lixar, requadrar, soldar, bobinar e rachar. A realização de todas estas etapas dependerá do tipo de acabamento empregado a matériaprima (aplicação do EVA) que está sendo finalizado. O funcionário pega a placa de EVA e um palete para verificar a espessura inicial do produto com um equipamento conhecido por 'espessímetro' e em seguida o coloca sobre a bancada próxima a máquina rachadeira. Em seguida o operador empurra a placa de borracha em direção ao ponto de corte da máquina para ser dividida conforme o tamanho desejado, sendo que essas placas são produzidas de acordo com a demanda de mercado.

Logo após o procedimento anterior, as placas são retiradas manualmente da prensa de vulcanização e colocada sobre a bancada, onde é efetuado as reparações necessárias e posteriormente encaminhado ao local de armazenagem para resfriar naturalmente. Durante o processo de fabricação, as placas são inspecionadas, testadas e classificadas conforme a qualidade do material que foi produzido. Na figura abaixo pode ser observado o processo de trabalho em questão.

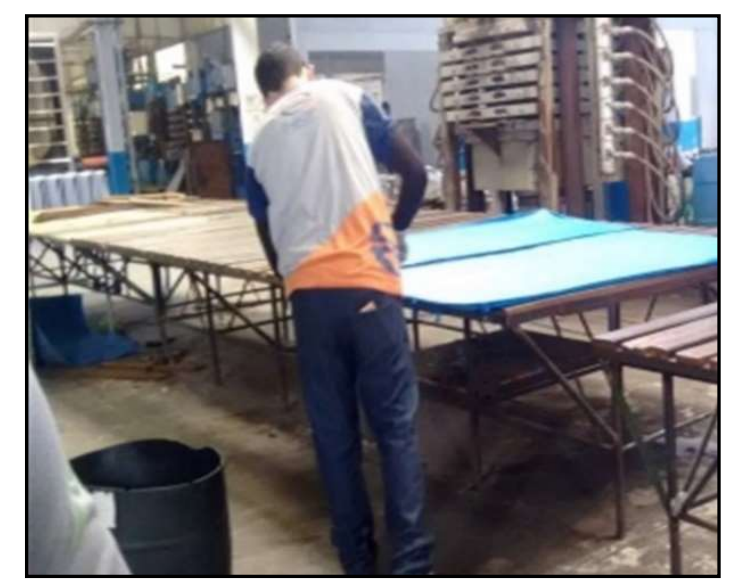

Figura 7: Posto de trabalho da rachadeira.

O funcionário desse posto de trabalho estava utilizando EPIs, como: luvas, botas, fardamento, porém, não utilizava protetor auricular. A jornada de trabalho desse colaborador é de $1 \mathrm{~h}$ para almoço e expediente diário de 8 h. O ruído aferido foi de $90 \mathrm{~dB}$ e o fator de iluminância de 136lux, sendo que tais medições também não estão em conformidade com legislação vigente. O recomendável de pressão sonora sem proteção durante uma jornada de trabalho de $8 \mathrm{~h}$ é de $85 \mathrm{~dB}$ e para esse ambiente laboral é preferível um fator de iluminância entre o intervalo de 500 a 1000 lux.

\section{CONCLUSÕES}

A presente pesquisa foi voltada ao estudo ergonômico do trabalho em uma fábrica de borrachas em Juazeiro do Norte (CE), com a finalidade de identificar, discutir e apresentar a existência da relação entre ergonomia e os problemas encontrados nos postos de trabalho, bem como na elaboração de proposta de melhorias para os processos produtivos avaliados.

Após a realização do estudo, algumas recomendações ficaram evidentes para a adequação 
ergonômica. No processo de pesagem, foi constatado que, no recinto, havia calor em excesso, os funcionários estavam utilizando alguns EPIs básicos, porém, não utilizavam o protetor auricular, que é um equipamento de extrema importância para proteção da audição.

Nesse recinto de trabalho é recomendável a introdução de ventilação diluidora e a instalação de coifas com a finalidade de amenizar a carga térmica que incide sobre o trabalhador. Também foi constatado que o colaborador realizava uma série de movimentos repetitivos durante a operação de pesagem, sendo que para essa atividade é aconselhável efetuar uma análise de tempos e movimentos para encontrar a melhor forma que o operador deve realizar essa atividade com mínimo de movimentos, o que evitaria uma possível fadiga muscular para esse operador futuramente.

No processo de mistura, a temperatura, também se encontra bastante elevada e poderia ser atendido com a instalação de exaustores, o que tornaria o ambiente mais favorável para o trabalho. Além disso, durante a visita à fábrica foi constatado que o local estava desorganizado com vários materiais misturados. Uma proposta seria organizar os itens, facilitando o trabalho e tornado o setor mais produtivo. A empresa também deve incentivar os funcionários a usarem os EPIs que forem fornecidos, principalmente, a importância do uso do protetor auricular.

De acordo com AET, percebe-se que os funcionários estão exercendo suas atividades profissionais com posturas inadequadas, sendo que os componentes a serem processados pelo misturador são colocados no piso próximo a máquina e com isso o colaborador necessita agachar-se todas as vezes para operar esse maquinário, o que acaba forçando a sua coluna vertebral. Desse modo, recomenda-se a instalação de uma bancada próxima a essa máquina para colocar a matéria-prima, assim, diminuiria a pressão sobre a coluna vertebral do operador. É necessário também a programação de pausas para descanso durante a jornada de trabalho e o fornecimento de assentos ergonomicamente adequados, que possam ser utilizados por todos os trabalhadores durante as pausas.

Em todos os postos de trabalho avaliados foi constatado ruído em excesso, níveis de iluminação inadequada e atividades extremamente repetitivas. No setor de calandragem, vulcanização, rachadeira e no de resfriamento poderia ser atendido com a instalação de exaustores e ventiladores com a finalidade diminuir o excesso de calor e providenciar assentos para descanso. Além disso, em todos os recintos de trabalho da fábrica, a empresa deve fornecer os equipamentos de proteção adequados (botas, luvas, fardamento, protetor auricular) e incentivar os funcionários a utilizá-los frequentemente.

Em relação iluminação desses setores seria ideal providenciar ou projetar um novo sistema iluminação com níveis iluminância adequado para cada atividade. Nos arredores dos maquinários existentes na fábrica deve também ser providenciado as devidas marcações de segurança no piso para evitar possíveis ocorrência de acidentes de trabalho.

Na fábrica, também deve existir uma área de enfermaria para atender os seus funcionários em casos de eventuais incidentes no trabalho. Vale ressaltar que as condições inadequadas identificadas nesse estudo estão embasadas na percepção dos funcionários que provavelmente não têm conhecimento teórico-técnico 
do conceito de ergonomia e em relação as adequadas condições de trabalho. Porém, é de extrema relevância considerar o conhecimento tácito dos entrevistados em relação as condições do seu ambiente de trabalho.

\section{REFERÊNCIAS}

ANDRADE, M. M.. Introdução à Metodologia do Trabalho Científico. 10 ed. São Paulo: Atlas, 2010.

ANTUNES, R.; PRAUN, L.. A sociedade dos adoecimentos no trabalho. Serviço Social \& Sociedade, n.123, p.407-427, 2015.

ASSOCIAÇÃO BRASILEIRA DE NORMAS TÉCNICAS - ABNT. NBR 5413: lluminância de interiores. Rio de Janeiro: ABNT, 1992.

BRASIL. Norma Regulamentadora 15: atividades e operações insalubres. Brasília: DOU, 1978.

BRASIL. Norma Regulamentadora 17: Ergonomia. Brasília: DOU, 1978.

DUL, J.; WEERDMEESTER, B.. Ergonomia Prática. 3 ed. São Paulo: Blucher, 2012.

FERREIRA, L. L.. Sobre a Análise Ergonômica do Trabalho ou AET. Revista Brasileira de Saúde Ocupacional, v.40, n.131, p.8-11, 2015.

GIL, A. C.. Como elaborar projetos de pesquisa. 5 ed. São Paulo: Atlas, 2017.

GUÉRIN, F.. Compreender o trabalho para transformá-lo: a Prática da Ergonomia. São Paulo: Blucher, 2001.

IIDA, I.. Ergonomia: projeto e produção. 2 ed. São Paulo: Edgard Blücher, 2005.

JANUÁRIO, T. L. S.; ARAÚJO FILHO, J. G.; OLIVEIRA, E. A. F.. Análise ergonômica da operação de rebitagem em panelas de alumínio. Revista Brasileira de Administração Científica, v.10, n.1, 2019
KROEMER, K. H. E.; GRANDJEAN, E.. Manual de Ergonomia: Adaptando o Trabalho ao Homem. 5 ed. Porto Alegre: Bookman, 2005.

LOURINHO, M. G.. Riscos de lesão musculoesquelética em diferentes setores de uma empresa calçadista. Fisioterapia e Pesquisa, v.18, n.3, p.252-257, 2011.

OLIVEIRA, E. A. F.. Diretrizes para o planejamento de saúde e segurança do trabalho nas futuras instalações de uma fábrica de velas. Revista Brasileira de Saúde e Segurança no Trabalho, v.1, n.1, p.1-14, 2018.

ORMELEZ, C. R.; ULBRICHT, L.. Análise ergonômica do trabalho aplicada a um posto de trabalho com sobrecarga física. Uniandrade, v.11, n.2, p.69-84, 2010.

PINTO, A. G.; TERESO, M. J. A.; ABRAHÃO, R. F.. Práticas ergonômicas em um grupo de indústrias da Região Metropolitana de Campinas: natureza , gestão e atores envolvidos. Gestão \& Produção, v.25, n.2, p.398-409, 2018.

RIBEIRO, M. H. A.. Avaliação ergonômica do trabalho em indústria de aço inox: análise de condições psicofisiológicas. Revista Brasileira de Medicina do Trabalho, v.14, n.2, p.143152, 2015.

SILVA, C. R.. Ergonomia: um estudo sobre sua influência na produtividade. Revista de Gestão USP, v.16, n.4, p.61-75, 2009.

TORRES, A. R. A.. Construção participativa de uma linha de cuidado ao trabalhador com Lesão por Esforços Repetitivos. Revista da Rede de Enfermagem do Nordeste, v.17, n.5, p.626-635, 2016.

A CBPC - Companhia Brasileira de Produção Científica (CNPJ: 11.221.422/0001-03) detém os direitos materiais desta publicação. Os direitos referem-se à publicação do trabalho em qualquer parte do mundo, incluindo os direitos às renovações, expansões e disseminaç̃oes da contribuição, bem como outros direitos subsidiários. Todos os trabalhos publicados eletronicamente poderão posteriormente ser publicados em coletâneas impressas sob coordenação da Sustenere Publishing, da Companhia Brasileira de Produção Científica e seus parceiros autorizados. Os (as) autores (as) preservam os direitos autorais, mas não têm permissão para a publicação da contribuição em outro meio, impresso ou digital, em português ou em tradução. 